\title{
Hagamos como que... \\ El Espacio de Juego en Sala de Internación Pediátrica*
}

\author{
Let's pretend that... \\ The playful area in a Pediatric Admission Room
}

\author{
Cecilia Vescovo** $^{* *}$
}

"Jugar nos ayudaba a entender la vida, y tambien el arte nos ayuda a entender la vida. Pero no porque los cuentos

'digan de otra manera' ciertos asuntos o expliquen con ejemplos lo que nos pasa sino por las consecuencias que trae habitarlos, aceptar el juego. Por esa manera de horadar que tiene la ficción, de levantar cosas tapadas. Mirar el otro lado. Fisurar lo que parece liso. Ofrecer grietas por donde colarse. Abonar las desmesuras. Explorar los territorios de frontera, entrar en los caracoles que esconden las personas, los vínculos, las ideas.” (Montes, 1999, pp 28-29).

\section{Resumen}

El presente trabajo analiza el Espacio de Juego de una Sala de Internación pediátrica para revalorizar la importancia y efectos de habitar el juego no sólo para el niño y la niña que allí se internan. Para ello, se recorre la historia del dispositivo, su momento instituyente; y viñetas donde no sólo la infancia atraviesa el jugar, también las personas adultas, acompañantes de la internación y el equipo de salud y sus prácticas.. El Espacio creaba las condiciones para la ficción, para entrar en otra escena, suspender el malestar y construir lazos. Ubicaba cuestiones diagnósticas y propiciaba operaciones subjetivas inaugurales. Constituido como otra escena para la institución, en una tercera zona, transformó la situación de internación hospitalaria en ocasión y oportunidad para la clínica y abrió camino al juego en todas sus

\footnotetext{
* El presente artículo fue reescrito sobre la base del Trabajo Integrador Final de la Carrera de Especialización en Psicología Clínica Institucional y Comunitaria (cohorte 2004 - 2005) "El Espacio de Juego de la Sala de Internación Pediátrica del Hospital Provincial de Rosario. Relatos y experiencias" (año 2009) del que soy autora y fue dirigido por la Dra. Ana Bloj.

** Psicóloga, Especialista en Psicología Clínica Institucional y Comunitaria. Trabaja en consultorio particular y cumple funciones en equipo interdisciplinario territorial de la Dirección de Salud Mental de la Provincia de Santa Fe.
} 
dimensiones, en niños y niñas, en adultos referentes -generalmente, madres- y las prácticas. Se revaloriza el jugar en sí mismo y la dimensión lúdica de las intervenciones y de la posición analítica.

Palabras clave: Espacio de juego - internación pediátrica - ficción - otra escena - clínica

\section{Abstract}

This paper analyzes a playful area of a Pediatric Admission Room at a Hospital to re - evaluate the importance and effects of inhabiting the game, not only for the boy and girl who are recovered there. To this end, we charted the story of the playful area, its foundational moment, vignettes in which not only children play, but also adults who accompany the internment, the health team and their practices. The playful area created the conditions for fiction, to be able to enter another scene, to suspend discomfort and to build social bonds. Diagnostic issues were identified there, and subjective inaugural operations were enabled. Set up as another scene for the institution, in a third zone, transformed the situation of hospitalization in an opportunity for the clinical practice, opening the door to the game in all its dimensions: among boys and girls, in adults concerned (generally mothers) and to all the practices. The game itself, the playful dimension of the interventions and the analytical position were enhanced.

Keywords: Playful Area - Internement Fiction - Other scene - Clinic

\section{Introducción}

El presente trabajo recupera escenas vinculadas a un dispositivo específico: el Espacio de Juego de la Sala de Internación Pediátrica de un Hospital de la ciudad de Rosario desde los inicios en 1993 hasta el 2008'. A partir de ellas, busca analizar determinadas marcas que le fueron propias.

La Sala de Internación Pediátrica posee características específicas y particulares. Se parte de cierta sanción de gravedad en el estado de salud, en este caso, en la infancia. El sufrimiento, el dolor, las intervenciones quirúrgicas e incluso la muerte forman parte de la sala. Por otro lado, la internación al ser conjunta, el niño y la niña se internan con un familiar, generalmente, la madre. Ambos se encuentran en un tiempo y un espacio diferentes al cotidiano, nuevo escenario que interrumpe el ritmo de vida habitual de todo el grupo familiar.

El Espacio de Juego fue gestado como dispositivo clínico de intervención para la Sala de Internación Pediátrica en el año $1993^{2}$. Se trataba de un espacio de encuentro colectivo sostenido principalmente por profesionales de psicología y del campo artístico, quienes convocaban semanalmente a jugar en la sala, desde la ficción y la creación, a niños, niñas y acompañantes referentes en la internación o familiares de visita, así como también a todo el equipo de salud. Si bien existen muchas experiencias que dan cuenta del entrecruzamiento de lenguajes para el abordaje clínico y mucho ya se ha escrito acerca de la función

\footnotetext{
${ }^{1}$ Año en el que fue realizado el trabajo (TIF) con las entrevistas y el material disponible hasta ese momento.

${ }^{2}$ Desde entonces, y con continuidad, fue el único dispositivo lúdico en sala hasta el año 2012, momento en el que se fueron sumando otros dispositivos.
} 
del juego y el jugar, sobretodo en el trabajo con la infancia, resulta relevante analizar este dispositivo clínico en su singularidad, recuperando escenas que permitan transmitir las marcas que ha dejado.

Para ello se analizaron, mediante un abordaje cualitativo interpretativo, diferentes materiales escritos sobre el dispositivo, publicados o inéditos (pertenecientes a la sala de pediatría del hospital y al equipo del Espacio de Juego); y diez entrevistas semi dirigidas, realizadas para la escritura del TIF, a quienes coordinaron el dispositivo entre los años 1993 y 2008. En las entrevistas se indagó acerca de las escenas del Espacio de Juego que recordaban representativas, los obstáculos encontrados, los efectos del dispositivo y la articulación con el equipo de salud.

El presente trabajo es la escritura de la lectura del material recopilado. Es el escrito de una lectura irrespetuosa, "levantando la cabeza" (Barthes, 1987) y sus anotaciones. Se hará un breve recorrido por la historia del dispositivo, resaltando en ese apartado tres dimensiones de la problemática: la madre y el niño/la niña, las madres entre sí, las madres y el equipo de salud. Por otra parte se recorrerán diferentes escenas de juego, también en tres niveles de análisis: infancias en la internación; madres o padres acompañantes de la misma; y el equipo de salud y sus prácticas o la institución misma atravesada por el jugar.

Todo el material analizado (nombres propios, cronologías, diagnósticos, registros, etc.) ha sido modificado en el presente escrito a los fines de preservar y resguardar la identidad de los sujetos implicados y la confidencialidad. Las viñetas elegidas son recreación personal y ficticia, intentando transmitir con ellas la singularidad de un Espacio de Juego, para recuperar una historia y las huellas de una experiencia; y revalorizar la importancia de la función del juego y del jugar.

\section{Construcción de un espacio.}

\section{Los inicios}

El Espacio de Juego en la Sala de internación Pediátrica surgió a partir de un proceso de trabajo que permitió la construcción de un equipo interdisciplinario. La Residencia de Post-grado -hoy Carrera de Especialización- realizaba su práctica clínica en la sala desde los comienzos de los años '90. En ese marco, se pensaba la interconsulta como la estrategia de inserción, se apuntaba a recuperar lo singular de la práctica y las coordenadas de la dimensión subjetiva. Desde la Residencia de Pediatría, incluir a psicólogas en el trabajo en sala implicó trabajar interdisciplinariamente y comenzar a pensar en otras herramientas para la práctica.

En un primer momento, la sala de internación contaba con quince camas. El familiar cuidador se internaba junto con el niño o la niña (internación conjunta) ocupando un pequeño espacio al lado de la cama que se encontraba junto a otras sin separación ni demasiado lugar para circular. A la preocupación por el estado de salud de quien se internaba y la interrupción en el cotidiano de toda la familia, se le sumaba el nivel de hacinamiento y la falta de intimidad en el espacio de la internación. El malestar era inevitable. A partir del trabajo que las psicólogas iban instalando en la sala, los pedidos de interconsulta aumentaron y las mismas madres (en su mayoría) internadassolicita- 
ron mayor atención de psicología. Necesitaban ser escuchadas, expresaban sentirse en una cárcel, querían hacer para salir de la pasividad y del encierro que la internación generaba (Bloj, 1996).

Por otra parte, al equipo de salud (enfermería y pediatría principalmente) le preocupaba diferentes situaciones en relación al familiar o referente de quien se internaba; como por ejemplo el trato poco afectivo y contenedor. El equipo refería cierto desentendimiento de parte de la persona adulta respecto de su función, referían que no se ocupaba demasiado y muchas veces permanecía en una posición de excesiva pasividad y ausencia, con la mirada abúlica frente al televisor, por ejemplo. En relación con pares, preocupaba la rivalidad y las reiteradas escenas de violencia con situaciones de agresión física a veces protagonizadas por madres o padres. $\mathrm{Y}$ por último, preocupaba al equipo médico la ausencia de preguntas respecto de la enfermedad de su hijo/a, el diagnóstico, el proceso de curación y pronóstico, lo cual era interpretado como desinterés, pasividad y poca colaboración de parte del familiar cuidador (Bloj, Copello, González, Meneghini, \& Villagra, 1994).

En ese contexto, y en la búsqueda de nuevos modos de intervención frente a este malestar, se pensó en el juego como estrategia de abordaje clínico institucional. A partir de un convenio con profesionales de teatro y títeres de la ciudad, se convocó a una actriz, titiritera y profesora de teatro y títeres - quien sostuvo el espacio hasta el 2005 - para que pudiera aportar herramientas lúdicas desde otro lugar y junto con las psicólogas residentes se instituyó un nuevo espacio de intervención clínica en la sala: El Espacio de Juego.

El espacio consistía en convocar a referentes que acompañaban la internación a construir/hacer un juguete u otro objeto con materiales ofrecidos. Era un tiempo de construcción de espacios mediadores a través de objetos para el intercambio (juguetes, dibujos, cartas o portarretratos, por ejemplo). A veces era para quienes se internaban, otras para acompañantes de la internación presentes, o para el equipo de salud y también para regalar a quienes estaban afuera de la internación. El dispositivo en la sala implicó generar un corte en la monotonía de la internación, creando un tiempo y un espacio diferente: entre un adentro -la internación- $\mathrm{y}$ un afuera, entre un tiempo que no pasaba y un día a la semana en que algo comenzaba a pasar.

La teatralidad en ese primer momento del dispositivo no estaba en el armado de escenas durante el espacio de juego ${ }^{3}$, sino que estaba en ese gesto de irrupción en la sala con canciones, colores, formas y tamaños, convocando a construir objetos notoriamente diferentes de los que habitan el escenario habitual de una sala de internación.

Cuando aquellas madres pedían hacer algo para salir de la monotonía, o porque allí en la sala se sentían en una cárcel, pedían recuperar el vivir creador. La apercepción creadora es lo que permite que el sujeto sienta que la vida vale la pena vivirse (Winnicott, 1972). Sin creación, en cambio, el sujeto se encontraría adaptado a una vida monótona, en donde no habría más que supervivencia (Mannoni, 1980).

\footnotetext{
${ }^{3}$ Como sí se puede ubicar en un tiempo posterior y se analiza en el siguiente apartado.
} 
Aunque la primera reacción de las madres fuera el yo no sé hacer nada o yo nunca le bice un juguete, podían luego, con grata sorpresa, valorar lo producido y llevárselo al hijo/hija que había quedado en la casa al cuidado de otra persona. A partir de allí, podían habilitarse al hacer, preguntarse por sus posibilidades, por su lugar en tanto madres y por el valor que el jugar tiene en la relación con su hijo/hija. También comenzaban a preguntarle al equipo médico aquello que se desconocía sobre la enfermedad (Copello, 1994).

Por otra parte, la propuesta de construcción de títeres permitió mediatizar y posibilitar otro lazo entre aquellas mamás que se peleaban fuertemente dentro de la sala. Con los títeres construidos, y con la intervención de la titiritera, dos mamás hicieron pelear a los títeres que se insultaban.

En relación al equipo de salud, la puesta en marcha del Espacio de Juego también tuvo sus primeros efectos. Por un lado, el temor y la reticencia de Enfermería -que se oponía a la implementación del dispositivo ante la posibilidad de mayores riesgos de contagio- fue cediendo cuando pudieron ubicar que a partir del encuentro y los nuevos lazos entre las madres, ellas se apropiaban de un saber respecto a la internación de sus hijos e hijas y comenzaban a transmitirse medidas y cuidados higiénicos unas a otras. Por otro lado, el equipo de residentes de pediatría, tanto en el pase de sala como en las visitas al paciente, comenzaron a hablarle a niños y niñas en la internación por su nombre propio a partir de leerlo en un cartel colocado junto a la cama que cada mamá había construido durante una activi- dad del Espacio de Juego ${ }^{4}$.

Por lo tanto, la construcción de objetos en la sala ubicaba una separación y en el mismo movimiento la constitución de otros modos de lazos entre la madre y su hijo/ hija, entre las propias madres, y entre las madres y el equipo de salud.

\section{Otras escenas en la internación}

Entre jeringas, tubos de oxígeno y sondas nasogástricas, la infancia en un hospital generalmente está enchufada a máquinas o bombas dosificadoras. Es transfundida, operada, estudiada, reinternada o colostomizada. Al atravesar una enfermedad y tratamiento médico, niños y niñas se topan de repente no sólo con diagnósticos que no comprenden, sino también, en muchos casos, con quimioterapias, neutropenias, caída del pelo, corticoides - que engordan la cara, no dejan dormir y dan mucho hambre-, recaídas, barbijos, aislamiento (palabra que figura en un cartel colocado en la puerta de la habitación, anunciando esta situación a cualquiera que se acerque a ella).

¿Y las personas adultas? También nos topamos con esto, con lo insoportable que puede resultar la muerte de un niño o una niña. ¿Cómo cuidan madres y padres a un hijo/una hija entre tantos medicamentos, indicaciones, estudios y tratamientos? ¿En dónde quedó la singularidad de su cuidado? ¿Cómo trabajan profesionales ante lo indefectible de la muerte? ¿Cómo posicionarse ante un diagnóstico terminal en la infancia?

\footnotetext{
${ }^{4}$ Las psicólogas del primer grupo de coordinación recuerdan que se encontraban con madres que les escribían el nombre de cada hijo/a con birome en sus cuerpos hospitalizados.
} 
En este escenario médico, lo médico, en tanto que discurso, subjetiva, produce un cuerpo y constituye la enfermedad como causa (Clavreul, 1983). Es causa de malestar y sufrimiento en quien la padece y también de la intervención del equipo médico. Por otra parte, es un escenario en el que se evidencian los avances tecnológicos en las instrumentaciones, tratamientos y evaluaciones médicas. La instrumentalización implica necesariamente una objetalización del cuerpo, reducido a puro organismo. Esta desubjetivación se advertiría no sólo en el cuerpo de quien se enferma, desconociendo sus marcas singulares, su historia, sus decires, y significaciones; sino también en el equipo médico, muchas veces desimplicado o sustituido como puro instrumento, anonimizado en su intervención, borrado como persona (Clavreul, 1983).

El espacio de Juego en dicho escenario, con la irrupción del juego, objetos de colores, muñecos, títeres y música, constituye en sí mismo otra escena. Es otro espacio dentro del espacio hospitalario. Por esta razón, tendrá efectos subjetivantes en todos los actores implicados: en las infancias, en las personas adultas conjuntamente internadas y en el equipo de salud y sus prácticas; tres dimensiones desde donde se abordará a continuación la función del juego a traves del análisis de breves viñetas atravesadas por el jugar.

\section{a) Habitar el juego - Lucía}

La historia de Lucía fue paradigmática para el Espacio de Juego y la sala de internación. Con siete años debió internarse en una habitación en aislamiento, junto a su ma- dre y padre, a partir de diagnosticársele una enfermedad oncológica. Mientras la psicóloga trabajaba con ella en la habitación, afuera, en el pasillo y hall de ingreso de la sala, niños, niñas y familias se encontraban a jugar en el Espacio de Juego. Lucía, que se encontró repentinamente - a causa de la enfermedad-con un ojo morado, construyó, acompañada de la psicóloga, un títere y creó a partir de allí un personaje: la Pirata Enojada. Con el acompañamiento del Espacio de Juego, Lucía junto a su madre y su padre, creó una historia con otros personajes. "La historia de la Pirata" se transformó en una obra de teatro de títeres que, luego de solicitar la debida autorización para abrir la puerta de la habitación (¿de aislamiento?) $\mathrm{y}$ anunciar la función en un cartel fue compartida con toda la sala.. Desde el interior de la cama de la habitación de Lucía hacia afuera, la función de títeres se desplegaba hacia el público que estaba en el pasillo. Al poco tiempo de esta función, entró en escena otro personaje y mientras en la habitación Lucía ensayaba con los títeres, afuera, en el espacio de juego, construían entre todos afiches, gacetillas e invitaciones para la difusión. Lucía construyó títeres -en el trabajo clínico individual- porque afuera, en el espacio grupal del Espacio de Juego, se estaban construyendo títeres. En el títere de la Pirata no sólo estaba su ojo morado, como un parche negro, también estaba la posibilidad de abrir la puerta de su habitación de aislamiento, con esa historia, de la que todos se fueron apropiando. Lucía, con su Pirata Enojada, podía enojarse por lo que le pasaba, pero también podíacrear otra historia y compartirla, con el particular sostén y participación de su padre y madre. 


\section{- Carlos}

Este adolescente de 14 años no encontraba un espacio en la convocatoria a jugar del Espacio de Juego. Atravesaba un cáncer, y su brazo corría el riesgo de ser amputado.

Un día, como cualquier otro, en la sala se decía que había que extremar los cuidados por la presencia de bichos dando vueltas, refiriéndose a virus y bacterias. La propuesta desde el Espacio de Juego fue construir bichos con plastilina. Se repartió el material habitación por habitación, cama por cama, se acompañó la construcción bajo la propuesta que cada quien construyera su bicho con plastilina. La convocatoria del equipo incluyó un desfile de las producciones plásticas de bichos en una mesita con ruedas como escenario para circular por cada habitación. Cuando se llegó a la habitación de Carlos, el adolescente exclamó: "Me encanta la plastilina!". Ante tal entusiasmo, le dejaron material para que él también construyera su bicho. A la semana siguiente se encontraron con que Carlos había construido, con la ayuda de su madre, un Aguila negra. Pero Carlos estaba preocupado. Las alas grandes que le había construido a su águila corrían riesgo de romperse. Coordinadores del Espacio de Juego le sacaron fotos al águila y a partir de ese momento Carlos encontró el modo de empezar a participar de la propuesta colectiva, y jugar.

Un buen tiempo después a Carlos, finalmente, le amputaron el brazo. Internado, el adolescente permitió la entrada a su habitación del personaje clownesco ${ }^{5}$ con su valija

\footnotetext{
${ }^{5} \mathrm{El}$ personaje clownesco creado por un actor y profesor rosarino formó parte de la sala entre los años 2003 y 2011. Este personaje, alto, nariz roja o larga, con pantalones llamativos, casi siempre con sombrero, ingresaba a la sala con su maleta de juegos con
}

de mago. Luego de algunos trucos de magia en donde este mago hacía desaparecer y reaparecer objetos, Carlos exclamó: "A mí también me gusta la magia... pero se me fue la mano, ¡no me salió bien!", mostrando el brazo que ya no estaba al correr las sábanas.

El brazo no había desaparecido como por arte de magia. Por lo tanto, tampoco lo podría reaparecer. Su brazo no estaba en lo real, en una realidad que no es de ficción, en una realidad en su crudeza. Sin embargo, con el recurso del humor -cuya esencia consiste en el ahorro de cierto despliegue emocional (Freud, 1994)- Carlos pudo producir un efecto de creación de sentido y aligerar el afecto como podría haber sido en este caso el dolor, el enojo, el disgusto, la desesperación, la resignación o la impotencia, en él y en los otros.

\section{- Jimena}

Reinternada por una enfermedad crónica desde hacía mucho tiempo, Jimena había dejado de hablar. Su mutismo preocupaba y sorprendía a todo el equipo. La psicóloga evaluó que la niña, cuando no contaba con un tiempo que le permitiera anticiparse y prepararse ante determinadas intervenciones médicas, se angustiaba muchísimo. Avisarle un tiempo antes de cada intervención que le hicieran le fue permitiendo manejar algunos tiempos en lugar de verse sorprendida y asaltada por el otro.

Desde el Espacio de Juego se pensó en un cuento. Era la historia de un pueblo que vivía en silencio hasta que un niño llegaba

los que convocaba a jugar. A veces se ofendía, contaba sus problemas, discutía con algún compañero de equipo y hacía intervenir a enfermería, médicos y todo aquel que pasaba por ahí. 
y comenzaba a hablar y preguntar. Ante la convocatoria a dramatizarlo, ella decidió espontáneamente representar al niño y romper con el silencio del pueblo. Jimena no sólo manejó los tiempos de la improvisación en la dramatización del cuento, sino, además, era su única voz la que interrumpía el silencio y quienes hacían de habitantes del pueblo ¡la estaban haciendo callar! ${ }^{6}$ Había podido intervenir en la improvisación. $\mathrm{Ni}$ tímida, ni apurada, Jimena encontró el ritmo, su tiempo y espacio para intervenir - sin necesidad de que se le indicara el momento- en otro espacio que el de las intervenciones médicas. En esta otra escena, que la ficción había creado, Jimena era protagonista, sujeto activo, hablaba y quebraba el silencio generalizado.

\section{- Ricardo}

Ingresó al hospital con apenas tres años, por una enfermedad oncológica. Las dificultades para los padres de ceder a Ricardo, en el sentido de ubicar un espacio separado para él, se agudizaron con la irrupción de esta enfermedad. La madre se negaba a la colocación de la sonda nasogástrica. Ricardo, por los efectos secundarios de la quimioterapia, tendría rápidamente una mucositis (inflamación de la mucosa de la boca y/o garganta) que le impediría comer ${ }^{7}$ Al mismo tiempo, antes de que a este niño se le comenzara a caer el pelo - también como efecto secundario de la quimioterapia - la

\footnotetext{
${ }^{6}$ Recuerdan en las entrevistas quienes coordinaron en ese momento.

${ }^{7}$ La colocación preventiva de una sonda nasogátrica es una intervención habitual en estos casos para evitar un mayor sufrimiento y una posible desnutrición o deshidratación y se realiza antes de que los síntomas de la mucositis aparezcan y ya no pueda ser colocada.
}

madre y el padre se pelaron junto con su hijo. "Para que sufra menos", afirmaban. Las dificultades para estos padres de hacerle lugar al diagnóstico también se trasladaba al tratamiento, al ubicar como lo dañino y peligroso todo lo que viniera de afuera. Si bien no rechazaban el tratamiento que sabían necesario para su hijo, la quimioterapia era significada como aquello que hacía visible la presencia de la enfermedad a partir de los efectos secundarios como la caída del pelo o la presencia de una sonda.

Una tarde en el Espacio de Juego se jugó a La voz de mando. El payaso hacía de robot que obedecía las órdenes de quien quisiera pasar a controlarlo. Ricardo quiso participar. Con él se acercó la madre. Cuando Ricardo daba alguna orden, el payaso-robot obedecía, él era su voz de mando. Pero cuando la madre intentaba hacerlo, el payaso-robot no obedecía. La voz de la madre no era su voz de mando. La madre y Ricardo no tenían la misma voz.

Luego de dos años y tras un largo proceso de tratamiento, Ricardo falleció internado en otro hospital. Un tiempo después, la madre avisó por teléfono que esa misma tarde iría a llevar una bolsa con juguetes de Ricardo en el horario del Espacio de Juego.

\section{- Zona de juego. Lo singular/lo colectivo y el interior/ exterior}

En estas escenas evocadas por quienes coordinaron el Espacio, hay niños y niñas que atravesaron enfermedades complejas, graves y con tratamientos prolongados; pero también se transmite con qué recursos contaban y cómo intervenía el dispositivo lúdico cuando el juego se interrumpía como 
consecuencia o no de la enfermedad y la internación.

Los niños y las niñas juegan, crean un mundo que les es propio y diferente al de la realidad pero no por eso menos serio. Jugar es la actividad principal enla infancia. En el juego niños y niñas se comportan como poetas (Freud, 1992). También en el juegopueden reproducir activamente lo que han sufrido de manera pasiva, como analiza Freud respecto de la importancia del juego en la constitución subjetiva a partir del fort-da y el movimiento presencia-ausencia en relación a la elaboración de la situación psíquica penosa como era la ausencia de la madre en el juego del niño que él observa (Freud, 1975).

Lucía y Carlos construyeron sus objetos con los que jugar y transmitieron seriamente qué era aquello que les ocupaba. En ambos casos, la presencia de la figura sostenedora de la persona adulta que acompañaba era altamente significativa.

Con la plasticidad de la plastilina aparece Carlos, quien puede construir otro bicho menos contagioso que aquellos que tanto frecuentan los pasillos de un hospital en el discurso médico. Construye un águila, por quien podía preocuparse. Temía por sus alas. Por las alas del águila.

El juego permite ubicar cuestiones diagnósticas, no sólo porque concierne a la estructura de un sujeto sino también porque señala diferentes momentos por los que un niño o una niña -como en estas escenasatraviesa según el modo en el que dispone del juego y se articula. No siempre se dispone del juego y del significante y, si el juego es un artificio por el que el goce se transforma (Marrone, 2003), es reinstalando lo lúdi- co, abriendo camino al juego, que la escena mortífera de una niña enmudecida como Jimena se comienza a agujerear y horadar.

No se trata de ir a jugar con niños y niñas porque padecen una grave enfermedad o de interpretar sus juegos, sino de crear las condiciones para jugar, reubicando el valor que el jugar en sí mismo tiene.

Sobre el jugar, Winnicott (1972) refiere que se trata de un hacer, y que este hacer se da en una zona de juego. Es una tercera zona porque no es una adaptación a la realidad como así tampoco una negación a ella; no se encuentra ni adentro ni afuera del sujeto; no es realidad psíquica interna pero tampoco es el mundo exterior. En esta tercera zona que "se ensancha en el vivir creador y en toda la vida cultural del hombre" (p. 90), el niño y la niña reúnen fenómenos del mundo exterior y sin necesidad de alucinaciones los utiliza al servicio de la realidad interior.

Octave Mannoni (1979) trabaja el concepto de otra escena. Esta escena que se abre en el mundo exterior y pone en suspenso la realidad es "comparable a la escena teatral, al terreno del juego, a la superficie de la obra literaria", y tiene por función "tanto escapar al principio de realidad como someterse a él" (Mannoni, 1979, pp. 73-74); no está en el aparato psíquico ni en el mundo real.

La presencia real de un organismo enfermo, de lo sufriente, del dolor y de la finitud -inevitable en toda existencia humana aunque irrepresentable e innombrable cuando ocurre a una edad tan temprana- pueden ponerse en suspenso durante el juego. Y en ese mientras tanto que dura el juego es cuando otra cosa puede pasar. Lo 
que se intenta al jugar, es que el estar enfermo/a -hospitalizado/a y diagnosticado/a, tratado/a, enchufado/a, colostomizado/a, intervenido/a, etc.- se suspenda. Esta suspensión en el tiempo abre la posibilidad a otro espacio, donde se abre el juego de lo contingente. De eso se trata en la ficción. Ese hagamos como que... es una frase más que propiciatoria con la que niños y niñas se proponen iniciar una ficción, es la llave que da apertura para entrar en esa otra escena que es territorio del juego.

Estas cuestiones en relación al juego están presentes en toda clínica con niños, niñas y adolescentes y en el trabajo que el profesional psicólogo se proponga, aún en el contexto de la internación, con cada niño o niña en su singularidad que lo requiera. Sin embargo, en quienes coordinaron, insistía la siguiente hipótesis: de no haber estado el Espacio de Juego, determinados movimientos difícilmente se bubieran producido, al menos en los tiempos en los que se produjeron.

Sin dudas, para Lucía, más allá de lo posibilitador del trabajo clínico que la psicóloga sostuvo con ella, no hubiera sido lo mismo atravesar ese tiempo prolongado de aislamiento y gravedad de su enfermedad sin la presencia del Espacio de Juego. El Espacio de Juego creó ese otro espacio dentro del espacio institucional, con el que podía dialogar desde su habitación. Ese otro espacio le permitió crear el suyo y armar un puente.

En Ricardo, que no contaba con un espacio individual de trabajo, el recurso al humor, la mediatización que la ficción otorgaba y el encuentro con otros y otras en el Espacio de Juego, permitió para esta madre tolerar lo que en otro espacio hubiera sido intolerable y rechazado. Y es precisamente a ese lugar -el del Espacio de Juego- a donde vuelven a ceder los juguetes de su hijo. No los regalan, no se los sacan de encima, los donan, y no a cualquier lugar.

Del mismo modo impacta la escena de Jimena quien, habiendo rechazado trabajar con la psicóloga, elige ese momento del Espacio de Juego para decir, para pronunciarse, para expresarse de otro modo que no fuera de una manera muda.

Por otra parte, en algunas escenas, el Espacio de Juego hace de puente entre una situación de aislamiento - un interior casi impenetrable- y un exterior. Desde el punto de vista médico, sabemos que la habitación llamada de aislamiento implica que quien allí se interna precisa de cuidados extremos para evitar contagios. Se aislan de este modo las posibilidades de contraer una infección. La habitación de aislamiento aisla, evita el contacto -como una isla- con el resto de la sala (¿el continente?), ya que ésta puede ser extremadamente peligrosa. ¿Cómo ubicar en este aislamiento un cuidado y no un castigo?

Este punto es clave a la hora de pensar en aquellos tratamientos que muchas veces no producen el alivio inmediato en quien padece, como es el caso de los tratamientos oncológicos. En la sala de internación es posible encontrarse con una cantidad importante de niños y niñas atravesando enfermedades oncológicas.

Susan Sontag (2003) ubica que las principales metáforas respecto del cáncer refieren a la topografía, es una enfermedad del espacio. El cáncer se extiende, prolifera o se difunde y los tumores son extirpados quirúrgicamente. En el cuerpo se librará la batalla entre 
las células malas y las células buenas; entre un cuerpo extraño -que puede avanzar y crecer- y el resto del cuerpo que debe resistir no sólo ante este avance sino también ante los tratamientos que desde afuera combaten y frenan la enfermedad. Es muy común, al hablar del cáncer, que se emplee esta terminología bélica. Se bombardea y ataca a las células cancerosas. La "consecuencia más temida, aparte de la muerte, es la mutilación o amputación de una parte del cuerpo" (Sontag, 2003, p. 21).

Si esta enfermedad la padece - como en estos casos - un niño o una niña, el modo en el que ella y su correspondiente tratamiento sea significado, dependerá en gran medida de la significación que las personas adultas le otorguen. En Ricardo, la enfermedad amenazó aislarlo de la posibilidad de generar lazos o respecto de intervenciones de un equipo y determinadas prácticas de cuidado. Lucía, en un entorno de sostén y confianza, pudo jugar en la situación de espera y aislamiento que la enfermedad le implicaba. Ella jugó en un espacio -zona de juego- entre el aislamiento y el pasillo de la sala. El aislamiento no impidió ni interrumpió el juego, así como tampoco la aisló de la propuesta grupal y hacer lazos.

El espacio de juego en la sala opera en un entre. Entre lo singular y lo colectivo, entre un adentro y un afuera, se juega un dispositivo que es lúdico en sí mismo. Ante la dificultad de reunirse a jugar en el hall porque había que extremar los cuidados para evitar el contagio por los bichos dando vueltas, el Espacio de Juego produce un nuevo sentido y -metaforizando- crea. No hace de este obstáculo un impedimento, como diría Jorge Jinkis (1994), respecto de la institución. ¿Qué hacer con lo que hay? Jugar. El
Espacio de Juego juega, hace jugar jugando, mucho antes de que un niño/niña o sureferente adulto que acompaña se pongan a jugar. El Espacio de Juego instala esa zona de juego y es desde allí que produce efectos. Abre el espacio para la ficción desde que ingresa a la sala a jugar con lo que se encuentre y eso moviliza cuerpos e instituidos, porque si hay juego no hay inercia o rigidez sino plasticidad, como en las plastilinas o en la frase "hagamos como que.."

\section{b) La función del adulto desde el Espacio de Juego}

Dado que desde el inicio la convocatoria a jugar ${ }^{8}$ incluyó al familiar adulto que se interna con el niño o la niña, es posible recuperar escenas protagonizadas, principalmente, por las madres.

¿Qué lugar para el 'protagonismo' de una madre en un contexto en el que es el equipo médico el que, con su saber, curará a su hijo/a enfermo/a? ¿Cómo incluirse, cómo contarse en su proceso de curación? ¿Cómo alojarla subjetivamente cuando muchas veces ellas mismas no son nombradas ${ }^{9}$ ¿Con qué adulto nos encontramos?

\section{- Ilda, Liliana y las mamás}

Ilda era la mamá de un niño que, teniendo casi un año y pesando menos de cinco kilogramos, desconcertaba al equipo médico por la desnutrición grave, el retraso en

\footnotetext{
${ }^{8}$ Después de la primera etapa de inicio del proyecto en donde la actividad lúdica era la producción de objetos, el dispositivo fue adquiriendo una impronta más teatral y escénica a partir de un personaje de clown en la coordinación del dispositivo.

9 Se las suele llamar "mami" o "mamita"; o ellas mismas, cuando se les preguntaba por su nombre, daban el de su hijo internado.
} 
el crecimiento de la talla y la dificultad para la absorción de los alimentos. El equipo no hallaba explicación médica. Había sido hospitalizado en varias ocasiones desde temprana edad y alimentado mediante botón gástrico. No sólo no crecía, tampoco se expresaba, ni se reía, ni balbuceaba. Durante las internaciones, Ilda, en el Espacio de juego, iba y venía en la dinámica colectiva propuesta, como una niña que juega a las escondidas con timidez y picardía, pero, también, como pidiendo ser encontrada. Entre la desconfianza y la demanda de exclusivi$\mathrm{dad}^{10}$, en este juego de presencia/ausencia, Ilda fue recorriendo un lugar para ella. Y fue posible festejar el cumpleaños, sacarse fotos y mirarlas, compartirlas, ubicar cambios y mejorías. En otro momento, confianza mediante, Ilda - con cierta fragilidad en su constitución subjetiva- quiso actuar y armar una escena llevando al Espacio de Juego un personaje que había inventado. En el hall de la sala de internación, disfrazada, comenzó a contar una historia ante todos los presentes convocados, con una ficción que no se sostenía mientras duraba la escena montada y por momentos se desarmaba, quedando poco claro cuándo entraba y salía de la misma. Junto con el trabajo que la psicóloga realizaba en articulación con otras disciplinas, mientras Ilda iba reconstruyendo su historia, ubicando los nombres de sus hijos e hijas, las edades, los lugares significativos, fechas y diagnósticos, iba, también, construyendo coordenadas subjetivantes, las coordenadas de tiempo y de espacio. Lentamente su hijo fue mejorando, comen-

\footnotetext{
${ }^{10}$ Se ofendió con el equipo cuando le dijeron que el festejo de cumpleaños que quería hacerle a su hijo en el Espacio de Juego sería compartido con otros.
}

zó a crecer, sonreír, pedir y llorar. Todo esto también sin explicación médica. Incluirla a Ilda en escenas de juego fue, seguramente, mucho más que entretenerla y convocarla a pasar un agradable momento ante tanto sufrimiento y desesperanza al escuchar las palabras médicas del ya no se puede hacer más nada.

Después de un juego colectivo en la hora del Espacio de Juego, Liliana, que había perdido, tuvo - como prenda - que improvisar una escena de telenovela con el personaje clownesco, en la que se confesaba algo oculto:

\section{"Liliana lo recibe distante y lo increpa: ¿no} tenés que confesarme algo?

Clown: viste cuando te dije que me iba a la cancha... no fui...

L: ¿A dónde fuiste? (un poco enojada)

C: ¿Los chicos? (haciéndose el distraído)

L: i¿A dónde fuiste?! (Vuelve a insistir ya más enojada)

C: Viste que llego tarde... llego tarde porque...

L: ¡Decilo! ¡Confesalo! Ya se todo...

C: Tengo otra mujer...

Liliana lo echa rápidamente de su casa"'1.

Esta escena de improvisación teatral finaliza cuando sus actores y actrices salen de sus personajes, de la escena dramática, al reírse, junto con espectadores que aplauden. Ninguno de los presentes podría negar u olvidar que el escenario era un pasillo de la sala de internación pediátrica; o que esa misma tarde la oncóloga se reuniría con los padres de Manuela para dar un nuevo pro-

\footnotetext{
${ }^{11}$ Extracto del cuaderno de registro del Espacio de Juego entre 2005-2007.
} 
nóstico; o que ya no estaba Lucas a quien tanto le gustaba el Espacio de Juego; o que la misma Liliana - quien tuvo que improvisar con el payaso - estaba allí, comía y dormía allí, desde hacía tres semanas acompañando a su hijo Carlitos en el tratamiento de su enfermedad. La crudeza de esta realidad no era negada por el juego, pero sí podía ponerse en suspenso para darle paso a una ficción.

Durante la hora y media del Espacio de Juego se observó que había un grupo de mamás muy ocupadas en una conversación. Al preguntarles, contaron que estaban hablando de hacerle llegar una carta a Claudia, la mamá de Amalia que había fallecido después de un largo tratamiento y había vuelto a su pueblo. Y pidieron que el Espacio de Juego les proporcione los materiales para hacerla (cartulinas de colores, fibras, tijeras).

\section{- La ficción y los lazos}

Si bien la situación propia de internación conjunta interrumpe el ritmo de vida habitual de una familia y genera incertidumbre, angustia y dificultad para encontrar un lugar en el territorio médico, es posible advertir que muchas veces en la sala se encontraban adultos que nunca antes habían tenido un lugar. Como Ilda, había madres que quizás nunca le habían contado su propia historia a otro, nunca habían jugado, o festejado un cumpleaños, menos aún con torta, globos, juegos y fotos. El Espacio de Juego ante estas situaciones de cierta inermidad, ante adultos en posición infantil y por lo tanto con dificultades para alojar a un hijo/hija y amparar al recién nacido, se transformó en una herramienta privilegiada para pen- sar intervenciones que constituyeran actos fundantes. Allí era posible alojar al adulto e intervenir en el vínculo con el hijo al situar cuestiones que en otros espacios - por ejemplo el de un tratamiento individual sólo hubieran podido situarse después de un largo tiempo de trabajo (Bloj, Pullen, \& Grande 1999).

Por otra parte, en la escena de ficción protagonizada por Liliana nada hace referencia a un hospital y allí radica su valor, ya que podría tratarse de una escena típica de alguna clase de improvisación, de un taller de teatro o de un domingo por la tarde en una plaza con un grupo de teatro callejero. Nada refiere en ella al contexto en el que se desplegaba. Y sin embargo, es precisamente teniendo en cuenta ese contexto que se torna más significativa. ¿Cómo es posible que en una sala de internación una madre que tiene a su hijo enfermo, pueda jugar, reírse y actuar como en una telenovela?

Se trata de otra realidad, la "realidad de ficción” (Volnovich, 2000, p. 37), que se desarrolla en un tiempo y espacio determinados entre quienes acuerdan que aquella realidad -la de la internación, la instrumentalización, la enfermedad, etc.- quede en suspenso durante ese momento. Como el mencionado dale que... o hagamos como que... de los niños y las niñas cuando proponen jugar. También en la escena teatral, como en el sueño, se abre un espacio, una grieta, para la ilusión y la creencia, ya que el teatro, en tanto heredero del juego, tiene su misma función. Ya se sabía que Liliana no era la pareja del payaso, y menos aún que el payasola engañaba; pero, aún así (Mannoni, 1979), actuaba como si lo fuera, y le preguntaba como si lo fuera y se enojaba como 
si lo fuera. Esto lleva rápidamente a pensar en los juegos dramáticos con el que niños y niñas juegan a ser grandes: ellos y ellas en el juego son una mamá, un papá, doctores, futbolistas, superhéroes, villanos, constructores, príncipes o princesas; juegan a ser grandes. El juego, allí, opera en relación a esta disimetría constitutiva para la infancia con la que se instala esa demora respecto del niño y la niña en relación a la persona adulta. Esa demora o espera es un 'todavía no’ en relación al tiempo de la adultez. En el juego a ser grande se lee esta demora, es posible jugar a ser grande gracias a que todavía no lo son y aún así pueden serlo, en la ficción. La ficción, esa "otra realidad" (Volnovich, 2000, p. 37), esa otra escena (Mannoni, 1979), que experimentan niños y niñas en el juego y el adulto en su vivir creador (Winnicott, 1972), al poner en juego el como si, introduce un espacio y tiempo diferentes. Introduce la espera, mediatiza y vela lo real. Se trata de una "construcción en el vacío” (Montes, 1999, p. 22).

Desde el Espacio de Juego, creando un lugar de intimidad y de confianza, se convocaba también a las personasadultas a jugar (creando objetos como en los comienzos o desde escenas teatrales después), a ficcionalizar, suspender el malestar y hacer lazo con otros semejantes. El Espacio de Juego permitía, justamente, que una madre, este Otro para el niño, encuentre en la sala un lugar de alojamiento. La institución puede alojarlas en tanto se trata de un lugar subjetivante. Por lo tanto, darle un lugar a esa madre que se encuentra internada con el niño es propiciar al mismo tiempo un lugar para el niño/la niña en tanto hijo/a. Porque no hay infancia si no hay allí un Otro cuidador que anticipe, un otro que - en tanto adulto- se ubique como referente.

Los tratamientos para enfermedades oncológicas o crónicas, por lo general, son largos, a veces se prolongan por años, discontinuados con momentos de internación o externación y consulta ambulatoria. Quienes coordinaron, evocaron en las entrevistas, diferentes escenas colectivas, de madres y padres que hacen grupo, se encuentran, se reúnen, comparten sus historias, motivos de internación, expectativas, temores y dudas; escenas de madres que charlan, conversan, se conocen y hasta se hacen amigas. En algunas ocasiones hasta podían ayudarse entre ellas, para que una fuera a ver a hijos/hijas que estaban en sus casas, unas horas y volviera, mientras otra madre de la cama de al lado cuidaba a quien quedaba en el hospital en su internación. Se iban ayudando a ser madres, se ayudaban en el cuidado de sus hijos e hijas, en el ejercicio de la función. Si bien podríamos decir que los lazos se generaban espontáneamente, por la misma convivencia en la sala, la convocatoria del Espacio de Juego que se sostenía en lo grupal, la dimensión de lo colectivo que atravesó desde el inicio la propuesta posibilitaba el encuentro entre pares y propiciaba el lazo afectivo. Estos lazos podían permanecer aún cuando el espacio de juego no estuviera porque también se podían apropiar del espacio creado y del clima producido en la sala. El espacio de juego no sólo mediatizaba conflictos a través de la ficción sino que a su vez propiciaba que se generaran lazos más próximos al encontrarse de otro modo y comenzar a conocerse.

En este punto cabe entonces preguntar: 
¿Qué sucedía con el equipo médico al encontrarse con madres y padres que participaban, preguntaban, se acompañaban, discutían, festejaban, hacían grupo, proponían y se expresaban? ¿Cómo impactaba este nuevo posicionamiento de las y los referentes adultos? ¿Cómo retornaba hacia el equipo médico y hacia enfermería la participación de madres y padres en la Sala de Internación Pediátrica?

\section{c) A jugar la institución \\ - Abrir el debate para ir a jugar}

Antes de comenzar una jornada del Espacio de Juego, a una mamá le faltaba su billetera. Ante esta situación de angustia, mamás y papás se acercaron y el equipo propuso abrir el debate en relación a las normas de seguridad. Hablaron de la pertenencia y la participación en la sala, del cuidado de los hijos y las hijas y también de lo público en un hospital. Respecto de los reiterados robos, el equipo médico ya había elevado nota a la Dirección del hospital. Sin embargo, a partir de ese debate, familiares decidieron redactar y hacer circular una nota juntando firmas, transmitiendo la preocupación, para que fuera anexada a la enviada por el equipo médico. Esta nota firmada por familiares, con copia a Enfermería y Pediatría, fue formalmente presentada a Dirección por mesa de entradas.

El equipo de coordinación del Espacio de Juego pensó continuar con lo surgido en el debate y propuso -con el acuerdo del equipo médico- trabajar el reglamento de la sala. A partir de este nuevo debate se pudo despejar el pedido de que hubiera más pediatras en las urgencias y ubicaron que lo que generaba mucha angustia era no saber muy bien a quién recurrir en determinados momentos ante la búsqueda de información o explicación respecto al estado de salud del niño o de la niña. El Espacio de Juego podía funcionar como articulador entre las familias y pediatras.

En otra ocasión, el equipo de coordinación del Espacio de Juego instaló un buzón, el Burón del espacio de juego, en el hall de ingreso a la sala. Allí se invitaba a dejar lo que se deseara (cartas, dibujos, saludos, deseos, inquietudes, poemas, recuerdos, quejas o canciones entre tantos). Un mensaje que habían dejado en el buzón decía al final: “... que nos dejen tomar mate aunque sea una hora. Porque es algo necesario para todas las mamás de pediatría". Luego de leerlo en voz alta antes de comenzar a jugar en el Espacio de Juego, surgió el debate respecto de lo que era posible y no en la sala. Enfermería, que estaba escuchando, sintió el cuestionamiento. ¿Cómo hacer jugar determinados instituidos sin que esto a su vez genere resistencias? El equipo del Espacio de Juego propuso, entonces, jugar con el reglamento. Inventaron "El juego del Espacio de Juego" en el que -al modo del juego de la Oca- había premios y prendas con preguntas que los y las participantes debían contestar, referidas a la sala de Internación.

En el buzón también se encontraron varias cartas dirigidas a pediatras y enfermeros/as de la sala escritas por un grupo de madres. En ellas, cada pediatra y enferme$\mathrm{ro} / \mathrm{a}$ era nombrado/a individualmente por el nombre propio y alguna característica singular, a veces con tono de humor. Otra vez la firma era la misma: "Las madres de Pediatría”. En estas cartas había un juego en relación al nombre, al anonimato, lo colec- 
tivo y la singularidad. Es posible reconocer allí, en ese gesto, una valiosa intervención en varias direcciones. Los y las pediatras salen del anonimato o del nombramiento según la jerarquía que toda residencia médica establece (R1, R2 y R3) y pueden leerse cómo llegan a cada paciente y su familiar desde su singularidad. Casi al modo de un pase de sala, el conjunto de madres -en ese caso- describe cómo es cada pediatra de la sala. Y por otra parte, el anonimato al que comúnmente son convocadas las madres en una sala de internación se interpeló cuando apareció resaltado -casi irónicamente- bajo la firma colectiva. En este punto hubo un movimiento al pasar de ser una mami más (sin nombre, sin edad, sin historia) a estar incluida en una firma colectiva que ya implica una nominación, las madres de pediatría, que las aloja. En esa firma se lee el lazo y por ende, sin perder la singularidad, la acción colectiva del grupo posibilita un lugar en la trama, en esa red en la que es posible alojarse.

Estas situaciones muestran no sólo el nivel de protagonismo de las familias en la sala al ir apropiándose de ese espacio a través del juego, sino también cómo esto incide en lo institucional y puede producir cuestionamientos y algún movimiento en relación a la práctica médica.

A partir de que una residente de pediatría le regalara a un paciente un diploma que decía "paciente modelo", el Espacio de Juego realizó un cuestionario en una jornada del espacio en forma de parodia titulado "En busca del Paciente Modelo. Hacia una Nueva Pediatría". Allí se preguntaba a cada internado/a y su familia los datos filiatorios pero, también, si le gustaba que lo/la pincharan, quién prefería que lo/la atendiera, si dormía de noche o si le gustaba la comida del hospital, por ejemplo. Este juego habilitó, luego, que los y las residentes de pediatría se preguntaran respecto de aquello que es ser buen paciente. En el espacio de reuniones que en aquel entonces se instalaron conjuntamente entre residentes, psicólogos/as y espacio de juego, se trabajó acerca de ciertos ideales de la propia práctica. ¿Ser buen pediatra es soportar sin angustiarse la muerte de un paciente? ¿Un buen paciente es quien acepta las intervenciones y no se queja, no llora o no grita?

- Repensar las propias prácticas y la conformación de equipo

Este dispositivo clínico desde sus fundamentos se concibió incluyendo el entrecruzamiento de lenguajes. Una clínica con otros y otras implicaría este ejercicio de pensar la práctica, pensar aquello que se hace, con otros y con otras. Este pensar la práctica se anclaba en dos espacios diferenciados y valorados por los coordinadores en las entrevistas realizadas: el retrabajo posterior entre quienes coordinaban el Espacio de Juego, y las reuniones institucionales con residentes de pediatría. El retrabajo fue valorado como aquel tiempo posterior necesario e indispensable de reelaboración de las escenas ocurridas en la zona de juego. Se ensayaban registros y modos para la transmisón al equipo médico. La participación del Espacio de Juego en el espacio institucional de reunión con el equipo médico implicó -no sin dificultades- ser partícipe de las estrategias de intervención que mejorasen la internación de niños, niñas y su referente o acompañante, y también implicó apostar a 
la construcción de un equipo de salud. $\mathrm{Al}$ equipo inicial de psicólogas les permitió encontrar un lugar de inserción para transmitir cuestiones referidas a pacientes según lo ocurrido en el Espacio de Juego. Más adelante, fue clave para pensar el modo en el que un paciente se construye. El Espacio de Juego aportaba elementos para el diagnóstico de situaciones que el equipo de salud abordaba, o detectaba otras situaciones que no habían sido registradas aún.

La transmisión al equipo médico de lo producido en y por el Espacio de Juego no ha sido cuestión sencilla. En la situación de la niña Lucía se produjo una transmisión en acto de lo que este Espacio podía generar. El despliegue escénico, la riqueza de lo producido, la participación de toda la sala, y una niña que jugaba y creaba a pesar de padecer una grave enfermedad, permitieron -más allá de cierta fascinación- que se convirtiera en un caso paradigmático. Los y las residentes de pediatría de aquel momento muchas veces reticentes a participar del juego, por excesode trabajo, con sobrecargas de exigencias y angustia por diferentes situaciones-demostraron valorar la pertinencia de este Espacio de Juego y los efectos del jugar. Esto les permitió jugar a ellos y ellas también, detenerse, hacerse un espacio para otro encuentro con ese niño, esa niña o con esa familia y preguntarse respecto de su práctica.

\section{Reflexiones finales}

Las escenas evocadas transmiten de algún modo el lugar y la importancia del juego en términos generales $y$, particularmente, los efectos del jugar en una Sala de
Internación Pediátrica. Proponer jugar en el escenario médico tenía efectos subjetivantes no sólo en los niños y niñas, sino también en referentes cuidadores con quienes se internaban. El niño y la niña que juega durante una internación pone en suspenso el malestar que esto y su enfermedad le acarrean; abre paso al juego significante y toda la operatoria que conlleva. Las personas adultas que acompañan la internación también pueden jugar y experimentar el vivir creador en el juego, en donde están "en libertad de ser creadores" (Winnicott, 1972, p. 79).

A partir del juego y la ficción, creando un lugar de intimidad, confianza y encuentro con otros, el Espacio de Juego creó las condiciones para hacer de la sala de Internación un lugar de alojamiento y construcción de lazos. En muchos casos propició inaugurales operaciones subjetivantes, transformando la situación de internación hospitalaria en ocasión y oportunidad para que algo nuevo emergiera.

El jugar en la sala de internación abría otro espacio de posibilidades poniendo en suspenso el malestar y el sufrimiento, pero también las certezas y los instituidos. En este sentido se jugaba una práctica. El juego abre camino a otras escenas posibles e interpela lo que de institución hay en las prácticas cuando los discursos y teorías se rigidizan, cuando los ideales dirigen o cuando todo parece impedimento. Con cada acto creador, verdadero acontecimiento, se recupera la dimensión de lo contingente -aquello que puede ser diferente de lo que es- de todo movimiento instituyente. El Espacio de Juego, con una historia que le es propia, un origen o momento instituyente de 
creación y construcción, no es la puesta en marcha de un modelo, receta o método. Su construcción misma fue una intervención, un gesto creador e instituyente; una otra escena para la institución, que abrió el camino del juego en todas sus dimensiones, impactando también sobre la propia práctica clínica. El espacio de juego funcionó como esa tercera zona, espacio potencial, de la que Winnicott hablaba, transformando la sala de internación en un espacio oportuno para que se produjeran operaciones clínicas, verdaderos actos fundantes sólo ubicables por sus efectos.

Los psicólogos y las psicólogas que han pasado por la coordinación de este espacio en las entrevistas revalorizaron ese otro lugar desde donde se intervenía en el Espacio de Juego, porque les permitía circular de otro modo en la sala, intervenir desde otro lugar. Ese otro lugar diferente al espacio clínico individual ha dejado una marca en tanto experiencia de transmisión para el ejercicio del psicoanálisis, no sólo con niños y niñas. ¿A qué lugar 'otro' se estarían refiriendo? ¿otro lugar respecto de cuál?

Si fue posible sorprenderse cuando Jimena comenzó a hablar, cuando esa mamá regaló los juguetes de su hijo, cuando Ilda quiso actuar, cuando se leía una carta del buzón, es porque se había podido jugar, suspender cierto saber y permitir que fuera posible algo diferente, con valor de verdadero acontecimiento. Lacan (1965) dice "lo propio del juego es que antes que se juegue, nadie sabe lo que va a salir de él" (p. 76). ¿No es acaso esto lo que también ocurre con una intervención analítica? El juego atañe al psicoanálisis, al quehacer del psicoanalista, pero no para ser interpretado o analizado, sino por su valor en sí mismo.
Lo lúdico es parte del psicoanálisis y de la posición analítica. Por lo tanto, recuperar e instalar la dimensión lúdica de todo acto; ubicar la importancia de abrir el juego, de la posición lúdica en el quehacer analítico, del jugar en cada intervención, instalar el juego -movimiento- en la clínica han sido, quizás, las marcas más importantes que este espacio ha dejado.

\section{Referencias}

- Barthes, R. (1987). El susurro del lenguaje. Más allá de la palabra y la escritura. Barcelona: Paidos.

- Bloj, A. (1996). Historia de un espacio de juego. En A. Seron, A. Bloj, J. Boccanera, \& L. Copello, Espacio de Juego. Aportes interdisciplinarios para las prácticas en salud infantil. Rosario.

- Bloj, A., Copello, L., González, G., Meneghini, M. B., \& Villagra, M. E. (1994). Internación, entre la enfermedad y el malestar. Un lugar para jugar. La Grieta, 14-16.

- Bloj, A., Pullen, S., \& Grande, S. (1999). Desnutrición infantil: intervenciones en la subjetividad en el marco de la internación y del consultorio ambulatorio. Investigaciones en salud 2.

- Clavreul, J. (1983). El orden médico. Barcelona: Argot Compañía del Libro S. A.

- Copello, L. (1994). Aportes desde el cruce de disciplinas para el abordaje de estrategias de prevención en salud infantil.

- Copello, L. (2002). La construcción en la adversidad: el acontecimiento teatral en una sala de internación pediátrica.

- Freud, S. (1992). El creador literario y el fantaseo. Buenos Aires: Amorrortu Edi- 
tores.

- Freud, S. (1975). Más allá del principio del placer. Buenos Aires: Amorrortu Editores.

- Freud, S. (1994). El humor. Buenos Aires: Amorrortu Editores.

- Jinkis, J. (1994). La acción analítica. Rosario: Homo Sapiens.

- Lacan, J. (inédito). Seminario XII "Problemas cruciales para el psicoanálisis", clase del 19/5/65. Recuperado de: http: / / www.bibliopsi.org/docs/lacan/15\%20Seminario \%2012.pdf.

- Mannoni, M. (1980). La teoría como ficción. Freud, Groddeck, Winnicott, Lacan. Barcelona: Editorial Crítica S. A.

- Mannoni, O. (1979). La otra escena. Claves de lo imaginario. Buenos Aires: Amorrortu.

- Marrone, C. (2003). Clase dictada en la Carrera de Especialización en Psicología Clínica, Institucional y Comunitaria. Material sin revisar por la autora.

- Montes, G. (1999). La frontera indómita. En torno a la construcción y defensa del espacio poético. México: Fondo de Cultura Económica.

- Sontag, S. (2003). La enfermedad y sus metáforas. Buenos Aires: Aguilar, Altea, Taurus, Alfaguara.

- Volnovich, J. C. (2000). Claves de infancia. Etica y género en la clínica psicoanalitica con niños. Rosario: Homo Sapiens.

- Winnicott, D. W. (1972). Realidady Juego. Barcelona: Gedisa. 